
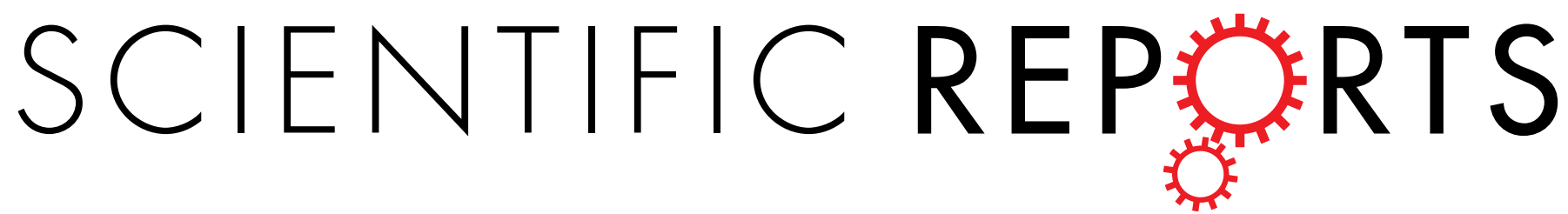

\title{
OPEN
}

Received: 15 December 2015

Accepted: 23 March 2016

Published: 13 April 2016

\section{The Efficacy of GnRHa Alone or in Combination with rhGH for the Treatment of Chinese Children with Central Precocious Puberty}

\author{
Mengjie Wang ${ }^{1}$, Youjie Zhang ${ }^{2}$, Dan Lan ${ }^{3}$ \& Jennifer W. Hill ${ }^{1,4}$
}

The addition of recombinant human growth hormone (rhGH) to GnRH agonist (GnRHa) to treat central precocious puberty (CPP) is controversial. We systemically reviewed and evaluated the efficacy and safety of the rhGH and GnRHa adjunctive therapy in Chinese children with CPP and assessed the influence of age and therapy duration on the efficacy of the combined treatment. A total of 464 patients were included from 14 studies. Compared with baseline, administration of $\mathrm{GnRHa}$ plus rhGH led to a significant increase in height, predicted adult height (PAH) and height standard deviation for bone age (HtSDS-BA), corresponding to a weighted mean difference (WMD) $(95 \% \mathrm{Cl})$ of $9.06 \mathrm{~cm}(6.41,11.70)$, $6.5 \mathrm{~cm}(4.47,8.52)$, and $0.86(0.58,1.14)$ respectively. Subgroup analysis showed the combined therapy had increased efficacy in subjects with initial treatment age younger than 10 years old or with treatment lasting over 12 months. Compared with $\mathrm{GnRHa}$ alone treatment, the combined treatment led to a significant increase in height, PAH and HtSDS-BA, corresponding to a WMD $(95 \% \mathrm{Cl})$ of $3.56 \mathrm{~cm}(2.54$, $4.57), 3.76 \mathrm{~cm}(3.19,4.34)$ and $0.56(0.43,0.69)$. The combined treatment exhibited no safety concerns. Our findings may aid clinicians in making treatment decisions for children with CPP.

Central precocious puberty (CPP) is defined as the premature activation of the hypothalamic-pituitary-gonadal axis with breast development before the age of 8 years in girls and an increase in testicular size in boys younger than 9 years old. CPP, also named gonadotropin releasing hormone $(\mathrm{GnRH})$ dependent precocious puberty, is progressive and is often accompanied by advancement of bone age and accelerated linear growth ${ }^{1,2}$. In 2010 , the prevalence of CPP was 55.9 per 100,000 girls in Asia with annual incidence of CPP ranging from 3.3 to 50.4 per $100,000^{3}$.

Gonadotropin releasing hormone analogs (GnRHa), the first-line treatment for CPP, briefly activates the hypothalamic-pituitary-gondal axis, but then suppresses the production of gonadotropin and consequent production of sex steroids. GnRHa use arrests pubertal progression, with variable regression of secondary sexual characteristics and decreased rates of linear growth and skeletal maturation, and consequently should improve final adult height ${ }^{4-7}$. However, several studies reported that GnRHa might also decrease height velocity below the age-appropriate normal range ${ }^{8-11}$. In some patients, the growth velocity $(\mathrm{GV})$ decrease was so marked that it impaired predicted adult height $(\mathrm{PAH})^{12}$. Detailed analyses of the growth hormone $(\mathrm{GH})$-insulin-like growth factor 1 (IGF-1) axis revealed that GnRHa treatment might decrease levels of free, biologically active IGF-1 $1^{13-15}$. GH stimulates hepatic IGF-1 production and release into the circulation. To compensate for the reduced spontaneous or stimulated secretion of GH and IGF-1 during GnRHa therapy, it would be logical to add recombinant human $\mathrm{GH}(\mathrm{rhGH})$ in combination with $\mathrm{GnRHa} \mathrm{a}^{9,16,17}$.

In 1991, Oostdijk and colleagues firstly demonstrated that after 18 months of combined treatment of GnRHa and rhGH, 3 girls with CPP and low velocity obtained an improvement of $\mathrm{PAH}^{18}$. Volta and coworkers reviewed

${ }^{1}$ Center for Diabetes and Endocrine Research, Department of Physiology and Pharmacology, University of Toledo College of Medicine and Life Sciences, Toledo, Ohio 43614. ${ }^{2}$ Center for Hypertension and Personalized Medicine, Department of Physiology and Pharmacology, University of Toledo College of Medicine and Life Sciences, Toledo, Ohio 43614. ${ }^{3}$ Department of Pediatrics, the First Affiliated Hospital of Guangxi Medical University, Nanning, Guangxi, 530021, China. ${ }^{4}$ Department of Obstetrics-Gynecology, University of Toledo College of Medicine and Life Sciences, Toledo, Ohio, 43614. Correspondence and requests for materials should be addressed to J.W.H. (email: JenniferW. Hill@utoledo.edu) 
the combined therapy in CPP up to 2005 and demonstrated that this could benefit children with CPP and low GV to obtain a higher final height with a complete expression of genetic potential ${ }^{19}$. However, the Lawson Wilkins Pediatric Endocrine Society and the European Society for Pediatric Endocrinology suggested in 2009 that the addition of rhGH should not be recommended as a routine therapy due to lack of large-scale randomized, controlled trials evaluating the efficacy of the combined treatment ${ }^{7}$. Since then, little research has been done on the adjunctive treatment of GnRHa plus rhGH in children with CPP in western countries. In contrast, there are mounting studies investigating the efficacy of $\mathrm{GnRHa}$ and rhGH adjunctive treatment for patients with $\mathrm{CPP}$ in China since 2009. Several studies indicated that the combined treatment could significantly increase HtSDS-BA or PAH compared with the GnRHa alone ${ }^{20-25}$. However, their results were not consistent.

It is unknown whether the effects of GnRHa and rhGH adjunctive treatment on height are influenced by patients' demographics, including age, and treatment duration. We therefore performed a systemic review and meta-analysis to evaluate the efficacy and safety of the addition of GH to GnRHa in treatment of Chinese children with CPP and to assess the influence of age and treatment duration on the efficacy of the combined treatment for CPP.

\section{Materials and Methods}

Search strategy. We performed "Medline, Embase, the Cochrane Library, Wanfang Database, VIP Database, and China National Knowledge Infrastructure" searches for all potentially eligible studies. The following free words were used: (gonadotropin releasing hormone analogs or GnRHa) AND (growth hormone or GH) AND (central precocious puberty or CPP) without any limitation. The bibliographies of retrieved randomized controlled trials (RCTs), case-control studies, observational studies, meta-analyses, narrative review articles, and relative references were reviewed by the authors. All reports were screened based on their abstract and references from general reviews were identified.

Inclusion criteria. Citations selected from this initial search were screened for eligibility using the follow criteria: firstly, the study was RCT, case-control studies, or observational studies with at least one therapy arm consisting of GnRHa and GH adjunctive therapy; secondly, the patients were Chinese children with central precocious puberty characterized by the early maturation of the hypothalamic-pituitary-gonadal axis with breast development before the age of 8 years in girls and an increase in testicular size in boys younger than 9 years old ${ }^{1}$; lastly, the trial presented any outcome measure of height, PAH, or height standard deviation (HtSDS-BA) that could be included.

Data extraction. The following data were extracted directly from the included trials: first author, year of publication, study arms, number of the patients, age, therapy duration, intervention, and outcome measurements (height, PAH and HtSDS-BA), body mass index (BMI), and insulin like growth factor-1 (IGF-1). Adverse effects and number of patients that dropped out of each study were also extracted. Mean and standard deviation (SD) were extracted for each outcome measurement. When the SD was not stated, we generated it from the sample size and the standard error or the $95 \%$ CI for each trials described by the Cochrane handbook for systematic review of interventions (version 5.0.1)

Statistics. The weighted mean difference (WMD) for each continuous outcome was estimated to obtain a pooled measurement across studies. The WMD was first calculated as mean changes between the follow-up of the combined treatment and baseline, and then calculated between the combined treatment and GnRHa treatment alone. The effects of age and therapy duration on the overall estimates were assessed by meta-regression or stratification. Subgroup analyses were conducted by age (younger or older than 10 years old) and by therapy duration (shorter or longer than 12 months) to measure each outcome. Forest plots were generated to illustrate the study-specific effect sizes along with a 95\% CI. Heterogeneity across studies was measured by the Q-test. $P<0.1$ or $I^{2}>50 \%$ was considered to be significant heterogeneity ${ }^{27}$. The combined WMD was gained using random-effect model when the effects were assumed to be heterogeneous, otherwise the fixed-effects model was adopted ${ }^{28}$. Funnel plots as well as Egger's test (if $>10$ studies were included) were conducted to assess possible existing publication bias $^{29}$. In addition, sensitivity analysis was performed to assess whether the overall meta-analysis estimate was influenced by any single study ${ }^{30}$. All analyses were conducted using STATA (version 11). $P$ values were two-sided and significant when less than 0.05 .

\section{Results}

Characteristics of trials. 302 potential clinical trials were retrieved from published literatures; the trial selection process is presented in Fig. 1. Seven observational studies ${ }^{31-37}$ and seven case-control studies ${ }^{20-25,38}$ containing 464 patients that met the criteria were included in the analysis. Baseline demographic and clinical characteristics of the individual studies are shown in Table 1 and 2 . All the patients were girls except for two boys included in the study by Wei and colleagues. The mean age in Table 1 was the initial treatment age. The age of onset of CPP, provided by some of the included studies, ranged from 6.2 to 7.8 years old ${ }^{32,36,37}$. The treatment duration of GnRHa alone before the addition of rhGH is mentioned in Table 1 if data was provided. Some of the included papers mentioned criteria for the addition of rhGH to GnRHa: firstly, GV was lower than $4 \mathrm{~cm}$ per year ${ }^{25,33,34,36,38}$; secondly, there was no obvious improvement in $\mathrm{PAH}^{31,33,36,38}$; thirdly, GnRH stimulation test found hypothalamus-pituitary-gonadal axis was inhibited by the GnRHa alone treatment ${ }^{21}$. Five different types of rhGH and three doses of rhGH were prescribed among all included studies: $4.5 \mathrm{IU} / 1.7 \mathrm{mg}, 4 \mathrm{IU} / 1.33 \mathrm{mg}, 16 \mathrm{IU} / 5.3 \mathrm{mg}$. However, the dosing guide was the same: $0.1 \sim 0.15 \mathrm{IU} / \mathrm{kg}^{*}$ day (except Ma et al. prescribed $0.14 \sim 0.20 \mathrm{IU} / \mathrm{kg}^{\star} \mathrm{day}$ ), which means all the dosages ranged from $0.03 \mathrm{mg} / \mathrm{kg}^{\star}$ day to $0.05 \mathrm{mg} / \mathrm{kg}^{\star}$ day. Conversion between IU $/ \mathrm{kg}$ and $\mathrm{mg} / \mathrm{kg}$ was performed to facilitate comparisons between studies. Although the studies included were generally considered of good quality, none of the studies was a RCT. 


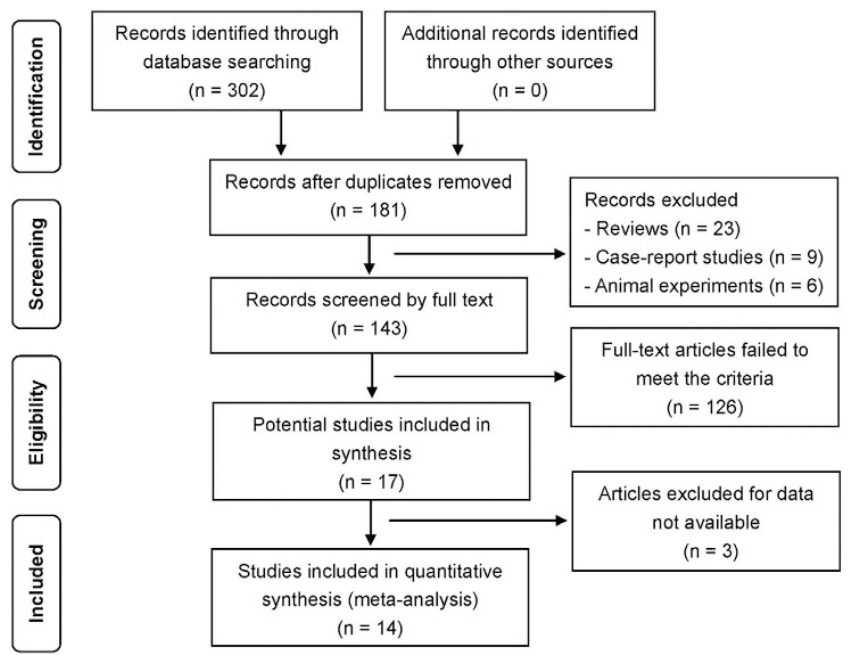

Figure 1. Flow chart showing the process of literature screening.

\begin{tabular}{|c|c|c|c|c|c|c|c|}
\hline First author Year & Study arms & $\begin{array}{c}\text { No. of } \\
\text { patients }\end{array}$ & $\begin{array}{l}\text { Mean age } \\
\text { (year) }\end{array}$ & $\begin{array}{l}\text { Study duration } \\
\text { (months) }\end{array}$ & Intervention & End points & $\begin{array}{l}\text { Adverse } \\
\text { effects }\end{array}$ \\
\hline Bai et al. ${ }^{31}$ & $\mathrm{GnRHa}+\mathrm{rhGH}$ & 26 & 10.5 & 17.3 & $\begin{array}{l}\text { GnRHa: } 90-110 \mu \mathrm{g} /\left(\mathrm{kg}^{\star} 28 \text { days }\right) \text { for } 3 \text { month, then } 60-80 \mu \mathrm{g} /\left(\mathrm{kg}^{\star} 28\right. \\
\text { days); } 6 \text { month later add rhGH: } 0.14 \mathrm{U} /\left(\mathrm{kg}^{\star} \text { day }\right)\end{array}$ & PAH and HtSDS-BA & No \\
\hline Liu et $a l .^{32}$ & $\mathrm{GnRHa}+\mathrm{rhGH}$ & 11 & 8.8 & 12 & $\begin{array}{l}\text { GnRHa: } 80-100 \mu \mathrm{g} / \mathrm{kg} \text { for first time, then } 60-80 \mu \mathrm{g} /\left(\mathrm{kg}^{\star} 28 \text { days }\right) ; 3 \\
\text { month later add rhGH: } 0.7-1 \mathrm{IU} / \mathrm{kg} \text { for } 6 \text { days per week }\end{array}$ & $\begin{array}{l}\text { Height, PAH and } \\
\text { HtSDS-BA }\end{array}$ & No \\
\hline Sun et al. ${ }^{33}$ & $\mathrm{GnRHa}+\mathrm{rhGH}$ & 60 & 10.5 & 6 & $\begin{array}{l}\text { GnRHa: } 100-120 \mu \mathrm{g} /\left(\mathrm{kg}^{\star} 28 \text { days }\right) \text { for first time, then } 50-100 \mu \mathrm{g} / \\
\left(\mathrm{kg}^{\star} 28 \text { days); rhGH: } 0.3 \mathrm{mg} / \mathrm{kg} \text { for } 6 \text { days per week }\right.\end{array}$ & $\begin{array}{l}\text { Height, PAH, and } \\
\text { HtSDS-BA }\end{array}$ & No \\
\hline Wu et al. ${ }^{34}$ & $\mathrm{GnRHa}+\mathrm{rhGH}$ & 18 & 9.7 & 14 & $\begin{array}{l}\text { GnRHa: } 80-100 \mu g /\left(\mathrm{kg}^{\star} 28 \text { days }\right), \leq 3.75 \mathrm{mg} ; 6 \text { month later add } \\
\text { rhGH: } 50-67 \mu \mathrm{g} /\left(\mathrm{kg}^{\star} \text { day }\right)\end{array}$ & PAH & Unclear \\
\hline Liu et al. ${ }^{35}$ & $\mathrm{GnRHa}+\mathrm{rhGH}$ & 30 & 9.4 & $>12$ & $\begin{array}{l}\text { GnRHa: } 80-100 \mu \mathrm{g} /\left(\mathrm{kg}^{\star} 14 \text { days }\right) \text { for one month, then } 80-100 \mu \mathrm{g} / \\
\left(\mathrm{kg}^{\star} 28 \text { days }\right), \leq 3.75 \mathrm{mg} ; \mathrm{rhGH}: 0.14-0.20 \mathrm{IU} /\left(\mathrm{kg}^{\star} \text { day }\right)\end{array}$ & $\begin{array}{l}\text { Height, PAH and } \\
\text { HtSDS-BA }\end{array}$ & No \\
\hline Ma et al. ${ }^{36}$ & $\mathrm{GnRHa}+\mathrm{rhGH}$ & 15 & 10.5 & 7.8 & $\begin{array}{l}\text { GnRHa: } 80-100 \mu \mathrm{g} /\left(\mathrm{kg}^{\star} 14 \text { days }\right) \text { for one month, then } 60-80 \mu \mathrm{g} / \\
\left(\mathrm{kg}^{\star} 28 \text { days }\right) ; 6 \text { month later add } \mathrm{rhGH}: 1 \mathrm{U} / \mathrm{kg} \text { for } 6 \text { to } 7 \text { days per week }\end{array}$ & $\begin{array}{l}\text { Height, PAH and } \\
\text { HtSDS-BA }\end{array}$ & No \\
\hline Fang et al. ${ }^{37}$ & $\mathrm{GnRHa}+\mathrm{rhGH}$ & 4 & 9.3 & 6 & GnRHa: $3.75 \mathrm{mg} / 28$ days; rhGH: $0.1 \mathrm{U} /\left(\mathrm{kg}^{*}\right.$ day) & Height and $\mathrm{PAH}$ & No \\
\hline
\end{tabular}

Table 1. Characteristics of seven observational studies included in the present meta-analysis. CPP: central precocious puberty; GnRHa: gonadotropin releasing hormone analog; rhGH: recombinant human growth hormone; PAH, predicted adult height; HtSDS-BA, height standard deviation score for bone age; BMI, body mass index; IGF-1, insulin like growth factor-1.

Outcome measurements. Effects of GnRHa plus rhGH adjunctive treatment for CPP. A total of 306 patients that compared the follow-up of the GnRHa and rhGH adjunctive treatment and baseline were analyzed. After administration of GnRHa plus rhGH, a significant increase in height, PAH, and HtSDS-BA was found, corresponding to a WMD $(95 \% \mathrm{CI})$ of $9.06 \mathrm{~cm}(6.41,11.70), 6.50 \mathrm{~cm}(4.47,8.52)$, and $0.86(0.58,1.14)$ respectively (all $P$ values $=0.000$ ) (Fig. 2). No long-term efficacy of the GnRHa and rhGH adjunctive treatment could be assessed due to the relatively short treatment duration among included studies. Nevertheless, we did an assessment after removing the shortest studies that had treatment duration of only 6 months. We found that compared with baseline, administration of $\mathrm{GnRHa}$ plus rhGH led to a more significant increase in height, $\mathrm{PAH}$ and HtSDS-BA, corresponding to a WMD (95\% CI) of $10.38 \mathrm{~cm}(8.60-12.17), 6.94 \mathrm{~cm}(5.34-8.54)$, and 0.92 $(0.68-1.17)$ respectively.

Meta-regression analyses were performed for separately investigating the influence of age and therapy duration on the change in each outcome measurement. Even though meta-regression did not show a statistical significance between the outcomes (height and HtSDS-BA) and subjects' age, negative trends were seen between the outcomes and subjects' age. A negative association was seen between the change in PAH and subjects' age $[\beta$ coefficient $=-1.51,95 \% \mathrm{CI}(-2.67,-0.36), P=0.015, \mathrm{n}=306]$. In addition, meta-regression did not show a statistical significance between the outcomes (PAH and HtSDS-BA) and treatment duration, but positive trends were seen between the outcomes and duration. A positive association was seen between the change in height and treatment duration $[\beta$ coefficient $=0.34,95 \% \mathrm{CI}(0.08,0.61), P=0.016, \mathrm{n}=261]$. These findings indicated that the efficacy of the combined treatment might be improved as the patient's age decreases or as the treatment duration increases.

In the subgroup analysis based on age, larger improvements were observed among patients with younger initial treatment age ( $<10$ years old, as compared with $>10$ years old) with respect to height $(10.19 \mathrm{vs} .4 .71 \mathrm{~cm})$ and PAH (7.60 vs. $2.60 \mathrm{~cm})$ (Table 3). These findings indicated the combined therapy had increased efficacy in subjects younger than 10 years old. In the subgroups analysis based on therapy duration (12 months), larger 


\begin{tabular}{|c|c|c|c|c|c|c|c|}
\hline $\begin{array}{l}\text { First author } \\
\text { Year }\end{array}$ & Study arms & $\begin{array}{l}\text { No. of } \\
\text { patients }\end{array}$ & $\begin{array}{l}\text { Mean age } \\
\text { (years) }\end{array}$ & $\begin{array}{c}\text { Study duration } \\
\text { (months) }\end{array}$ & Intervention & End points & $\begin{array}{l}\text { Adverse } \\
\text { effects }\end{array}$ \\
\hline Luo et al. ${ }^{20}$ & $\begin{array}{l}\mathrm{GnRHa}+\mathrm{rhGH} \\
\mathrm{GnRHa}\end{array}$ & $\begin{array}{l}30 \\
30\end{array}$ & $\begin{array}{l}8.5 \\
8.5\end{array}$ & $\begin{array}{l}18.7 \\
19.6\end{array}$ & $\begin{array}{l}\text { GnRHa: } 100 \mu \mathrm{g} /\left(\mathrm{kg}^{\star} 28 \text { days }\right) \text { for first dose, then } 60-90 \mu \mathrm{g} /\left(\mathrm{kg}^{\star} 28 \text { days }\right) \text {; } \\
\text { rhGH: } 0.3 \mathrm{mg} / \mathrm{kg} \text { for7 days per week }\end{array}$ & $\begin{array}{l}\text { Height, PAH and } \\
\text { HtSDS-BA }\end{array}$ & No \\
\hline Wang et al..$^{38}$ & $\begin{array}{l}\text { GnRHa }+ \text { rhGH } \\
\text { GnRHa }\end{array}$ & $\begin{array}{l}31 \\
49\end{array}$ & $\begin{array}{l}9.0 \\
9.0\end{array}$ & $\begin{array}{l}25.3 \\
26.0\end{array}$ & $\begin{array}{l}\text { GnRHa: } 105-106 \pm 10 \mu \mathrm{g} /\left(\mathrm{kg}^{\star} 28-35 \text { days }\right) \text { for first dose, then } \leq 3.75 \mathrm{mg} ; 12 \\
\text { months later add rhGH: } 0.14 \pm 0.02 \mathrm{IU} /\left(\mathrm{kg}^{\star} \text { day }\right)\end{array}$ & $\begin{array}{l}\text { Height, PAH and } \\
\text { HtSDS-BA }\end{array}$ & No \\
\hline Zhang et al. ${ }^{23}$ & $\begin{array}{l}\mathrm{GnRHa}+\mathrm{rhGH} \\
\mathrm{GnRHa}\end{array}$ & $\begin{array}{l}20 \\
20\end{array}$ & $\begin{array}{l}8.4 \\
8.3\end{array}$ & $\begin{array}{l}20.2 \\
17.4\end{array}$ & $\begin{array}{l}\text { GnRHa: } 100 \mu \mathrm{g} /\left(\mathrm{kg}^{\star} 28-32 \text { day) for first dose, then } 60-90 \mu \mathrm{g} /\left(\mathrm{kg}^{\star} 28 \text { days }\right) \text {; }\right. \\
\mathrm{rhGH} 0.3 \mathrm{mg} / \mathrm{kg} \text { for } 7 \text { days per week }\end{array}$ & $\begin{array}{l}\text { Height, PAH and } \\
\text { HtSDS-BA }\end{array}$ & No \\
\hline Zheng et al..$^{25}$ & $\begin{array}{l}\mathrm{GnRHa}+\mathrm{rhGH} \\
\mathrm{GnRHa}\end{array}$ & $\begin{array}{l}26 \\
23\end{array}$ & $\begin{array}{l}9.1 \\
9.5\end{array}$ & $\begin{array}{l}30.8 \\
22.3\end{array}$ & $\begin{array}{l}\text { GnRHa: } 80-100 \mu \mathrm{g} /\left(\mathrm{kg}^{\star} 28-32 \text { day }\right) \text { for first two times, then } 60-80 \mu \mathrm{g} /\left(\mathrm{kg}^{\star} 28\right. \\
\text { days); } 19.4 \pm 11.8 \text { months later add rhGH: } 1 \mathrm{U} / \mathrm{kg} \text { for } 6 \text { to } 7 \text { days per week }\end{array}$ & $\begin{array}{l}\text { Height, PAH, and } \\
\text { HtSDS-BA }\end{array}$ & No \\
\hline Zhao et al..$^{24}$ & $\begin{array}{l}\text { GnRHa + rhGH } \\
\text { GnRHa }\end{array}$ & $\begin{array}{l}15 \\
15 \\
\end{array}$ & $\begin{array}{l}9.4 \\
9.3 \\
\end{array}$ & $\begin{array}{l}6 \\
6 \\
\end{array}$ & GnRHa: $65 \mu \mathrm{g} /\left(\mathrm{kg}^{\star} 28\right.$ days $) ;$ rhGH: $0.15 \mathrm{U} /\left(\mathrm{kg}^{\star}\right.$ day $)$ & Height and $\mathrm{PAH}$ & No \\
\hline Li et al. ${ }^{21}$ & $\begin{array}{l}\text { GnRHa }+ \text { rhGH } \\
\text { GnRHa }\end{array}$ & $\begin{array}{l}10 \\
11\end{array}$ & $\begin{array}{l}9.7 \\
9.3\end{array}$ & $\begin{array}{l}18.6 \\
16.9\end{array}$ & $\begin{array}{l}\text { GnRHa: } 100 \mu \mathrm{g} /\left(\mathrm{kg}^{\star} 28-32 \text { days }\right) \text { for three months, then maintaining dose is } \\
60-80 \mu \mathrm{g} /\left(\mathrm{kg}^{\star} 28-32 \text { days }\right) ; 3 \text { month later add } \mathrm{rhGH}: 0.23-0.28 \mathrm{mg} / \mathrm{kg} \text { for } 7 \\
\text { days per week }\end{array}$ & $\begin{array}{l}\text { Height, PAH and } \\
\text { HtSDS-BA }\end{array}$ & No \\
\hline Wei et al. $^{22}$ & $\begin{array}{l}\text { GnRHa }+ \text { rhGH } \\
\text { GnRHa }\end{array}$ & $\begin{array}{l}10 \\
10\end{array}$ & $\begin{array}{l}6.4 \\
6.5\end{array}$ & $\begin{array}{l}24 \\
24\end{array}$ & $\begin{array}{l}\text { GnRHa: } 100 \mu \mathrm{g} /\left(\mathrm{kg}{ }^{\star} 30 \text { days) for three months, then use lower maintaining }\right. \\
\text { dose; } 3 \text { month later add rhGH:0.7-1 ug/kg for } 7 \text { days per week }\end{array}$ & Height and PAH & Unclear \\
\hline
\end{tabular}

Table 2. Characteristics of seven case-control studies included in the present meta-analysis. CPP: central wprecocious puberty; GnRHa: gonadotropin releasing hormone analog; rhGH: recombinant human growth hormone; PAH, predicted adult height; HtSDS-BA, height standard deviation score for bone age; BMI, body mass index; IGF-1, insulin like growth factor-1.

improvements were observed between treatment lasting less than 12 months and over 12 months with respect to height $(10.85$ vs. $4.73 \mathrm{~cm})$ and HtSDS-BA (0.98vs. 0.45$)$. These findings indicated the combined therapy had increased efficacy in subjects treated longer than 12 months (Table 3 ).

Effects of GnRHa plus rhGH vs. GnRHa alone for CPP. To further evaluate the effect of rhGH on GnRHa treatment for CPP, we compared the combined treatment with GnRHa alone treatment. Seven case-control studies containing 142 patients in the combined group and 158 patients in the GnRHa alone group were analyzed. A fixed-effects model was used for analysis as we found there was no heterogeneity among the trials (all $P$ values $>0.1$ and $\left.I^{2}<50 \%\right)$. Compared with GnRHa alone treatment, administration of GnRHa plus rhGH led to a significant increase in height, PAH and HtSDS-BA, corresponding to a WMD $(95 \% \mathrm{CI})$ of $3.56 \mathrm{~cm}(2.54,4.57)$, $3.76 \mathrm{~cm}(3.19,4.34)$ and $0.56(0.43,0.69)$ respectively (Fig. 3$)$.

Publication bias. Publication bias was assessed by Egger's and Begg's test. No publication bias was observed in the funnel plot of 14 studies evaluating the height, PAH and HtSDS-BA during the comparison of the combined treatment with GnRHa alone treatment. In the analysis of PAH changes for the combined treatment vs. GnRHa alone, the resultant funnel shape was asymmetrical, indicating publication bias $(P=0.008)$. Sensitivity analysis was also conducted to test if the results are sensitive to restrictions on the data included ${ }^{30}$. During the comparison of the combined treatment with baseline, the mean change in PAH was $6.50 \mathrm{~cm}(4.47,8.52)$. The study of Sun and colleagues ${ }^{33}$ reported the largest variances in the change of PAH and the smallest increase in efficacy of the combined treatment vs. GnRHa alone treatment. Excluding this study from the analysis produced an estimate of change in PAH of $6.90 \mathrm{~cm}(5.47,8.34)$.

Adverse effects include a statement about the adverse effects reviewed for both GnRH and rhGH. Among girls with CPP, GnRHa are generally well tolerated. Transitory adverse complaints, including headaches, hot flushes, depression, and irregular menses, occur occasionally ${ }^{39}$. However, these events do not prevent continuation of treatment. Local adverse effects such as erythema, induration, wheal and sterile abscess formation occur in less than $15 \%$ of patients ${ }^{40}$. Evidence shows that bone mass density (BMD) might be decreased after GnRHa treatment in patients with central precocious puberty and/or short stature. In 2007, van Gool and colleagues found that after 3-year rhGH plus GnRHa combined treatment, short adolescent boys showed a trend towards decreased BMD ${ }^{41}$. However, the sample size in this study was small ( 6 treated and 2 control) and the results were not significant. Lem and colleagues did not see adverse effects on the BMD and body composition in short children born small for gestational age after rhGH to GnRHa adjunctive treatment ${ }^{42}$. Other possible adverse effects of rhGH include an injection-site reaction, rare nerve, muscle or joint pain, and an increased risk of diabetes ${ }^{43}$. Direct and powerful evidence is lacking for long-term evaluation of the safety of the addition of rhGH to GnRHa in patients with CPP.

To evaluate the safety of the GnRH plus rhGH treatment, we reviewed BMD, BMI, liver and kidney function tests, thyroid function tests, blood glucose tests, glycated hemoglobin Alc, insulin, blood tests, urine tests, $\mathrm{x}$-ray of the hand and wrist, abdominal and pelvic cavity ultrasound, and magnetic resonance imaging or computed tomography for determining occurrence of tumors. All included studies found no obvious adverse effects during and after the GnRHa plus rhGH combined treatment, although the changes of BMD could not be evaluated due to lack of data among all included studies. No statistical significance for BMI was found during the combined treatment (Fig. 4). Compared with baseline, administration of GnRHa plus rhGH led to a significant increase in IGF-1, corresponding to a WMD $(95 \%$ CI) of $39.31 \mathrm{ng} / \mathrm{ml}(30.77,47.86)$. The increased level of IGF-1 after combined treatment confirmed previous detailed analyses of the GH-IGF- 1 axis during the combined treatment ${ }^{13}$ and indicated that impaired height potential could be compensated for by the addition of rhGH to GnRHa. However, since only two studies showed IGF-1 levels after the treatment, we need more long-term evidence for the safety of the combined treatment. 
Study

ID

Luo et al. 2015 (20)

Wang et al. 2014 (38)

Liu et al. 2013 (32)

Sun et al. 2012 (33)

Liu et al. 2011 (35)

Ma et al. 2006 (36)

Fang et al. 2001 (37)

Zhang et al. 2012 (23)

Zheng et al. 2011 (25)

Zhao et al. 2011 (24)

Li et al. 2005 (21)

Wei et al. 2003 (22)

Overall (I-squared $=92.7 \%, p=0.000)$

\section{Height}

\begin{tabular}{cc|ccc} 
& & $9.06(6.41,11.70)$ & \\
\hline-18.2 & 0 & 18.2
\end{tabular}

\section{PAH}

Luo et al. 2015 (20)

Wang et al. 2014 (38)

Bai et al. 2013 (31)

Liu et al. 2013 (32)

Sun et al. 2012 (33)

Wu et al. 2012 (34)

Liu et al. 2011 (35)

Ma et al. 2006 (36)

Fang et al. 2001 (37)

Zhang et al. 2012 (23)

Zheng et al. 2011 (25)

Zhao et al. 2011 (24)

Li et al. 2005 (21)

Wei et al. 2003 (22)

Overall (I-squared $=94.2 \%, p=0.000$ )
WMD $(95 \% \mathrm{Cl})$

$12.04(10.34,13.74)$

$8.71(4.70,12.72)$

$4.70(4.21,5.19)$

$12.18(9.73,14.63)$

$5.70(1.19,10.21)$

$6.25(-0.85,13.35)$

$10.90(8.24,13.56)$

$6.80(3.89,9.71)$

$5.69(1.24,10.14)$

$9.30(3.03,15.57)$

$9.95(6.08,13.82)$

$9.06(6.41,11.70)$
$15.00(11.75,18.25)$

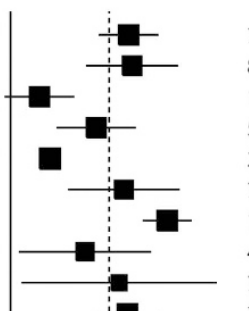

$7.77(5.81,9.73)$

$8.00(4.97,11.03)$

$1.90(-0.40,4.20)$

$5.64(3.03,8.25)$

$2.60(2.22,2.98)$

$7.46(3.78,11.14)$

$10.31(8.70,11.92)$

$4.90(0.55,9.25)$

$7.15(0.73,13.57)$

$7.69(5.81,9.57)$

$4.50(2.20,6.80)$

$6.27(3.81,8.73)$

$7.30(4.08,10.52)$

$9.59(8.16,11.02)$

$6.50(4.47,8.52)$

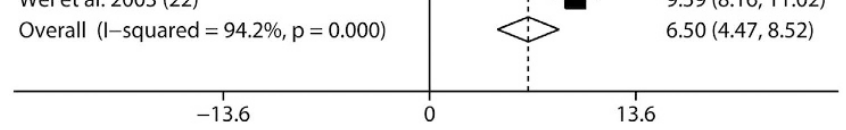

HtSDS-BA

Luo et al. 2015 (20)

Wang et al. 2014 (38)

Bai et al. 2013 (31)

Liu et al. 2013 (32)

Sun et al. 2012 (33)

Liu et al. 2011 (35)

Ma et al. 2006 (36)

Zhang et al. 2012 (23)

Zheng et al. 2011 (25)

Li et al. 2005 (21)

Overall (l-squared $=91.4 \%, p=0.000)$

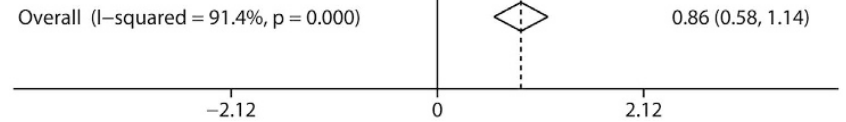

Figure 2. Random effects meta-analysis of GnRHa plus rhGH adjunctive treatment on Height, PAH and HtSDS-BA. The vertical line indicated no treatment effect. Squares and horizontal lines represent the point estimated with associated $95 \%$ CI for each comparison, respectively. Diamonds represent the random effects pooled WMD for each outcome. WMD, weighted mean difference; $\mathrm{PAH}$, predicted adult height; HtSDS-BA, height standard deviation score for bone age.

\section{Discussion}

Our meta-analysis shows a beneficial effect of GnRHa plus rhGH adjunctive therapy in Chinese children with CPP. The combined treatment was superior to either baseline or GnRHa treatment alone, corresponding to significant increases in height, PAH and/or HtSDS-BA. On subgroup analysis, the combined therapy had significantly increased efficacy in subjects with initial treatment age younger than 10 years old or with treatment lasting over 12 months. No apparent adverse effects occurred during the combined treatment in the published studies. This 


\begin{tabular}{|l|c|c|c|c|c|}
\hline End points & $\begin{array}{c}\text { Age/ therapy } \\
\text { duration }\end{array}$ & $\begin{array}{c}\text { No. of } \\
\text { subjects }\end{array}$ & WMD (95\% CI) & $\beta$ coefficient $\mathbf{9 5} \%$ CI) & P value \\
\hline Height & & 261 & & $-1.40(-3.41,0.61)$ & 0.153 \\
\hline & $<10$ years old & 187 & $10.19(8.43,11.94)$ & & 0.000 \\
\hline & $\geq 10$ years old & 75 & $4.71(4.23,5.19)$ & & 0.000 \\
\hline PAH & & 306 & & $-1.51(-2.67,-0.36)$ & 0.015 \\
\hline & $<10$ years old & 205 & $7.60(6.41,8.78)$ & & 0.000 \\
\hline & $\geq 10$ years old & 101 & $2.60(2.23,2.97)$ & & 0.000 \\
\hline HtSDS-BA & & 259 & & $-0.13(-0.48,0.22)$ & 0.412 \\
\hline & $<10$ years old & 158 & $0.99(0.70,1.28)$ & & 0.000 \\
\hline & $\geq 10$ years old & 101 & $0.57(0.29,0.86)$ & & 0.000 \\
\hline & & & & & \\
\hline Height & & 261 & & $0.34(0.08,0.61)$ & 0.016 \\
\hline & $<12$ months & 94 & $4.73(4.25,5.21)$ & & 0.000 \\
\hline & $\geq 12$ months & 168 & $10.85(9.14,12.56)$ & & 0.000 \\
\hline PAH & & 306 & & $0.19(-0.05,0.42)$ & 0.109 \\
\hline & $<12$ months & 105 & $4.85(2.61,7.10)$ & & 0.000 \\
\hline & $\geq 12$ months & 201 & $7.23(5.44,9.02)$ & & 0.000 \\
\hline HtSDS-BA & & 259 & & $0.04(-0.01,0.08)$ & 0.093 \\
\hline & $<12$ months & 86 & $0.45(0.39,0.52)$ & & 0.000 \\
\hline & $\geq 12$ months & 173 & $0.98(0.72,1.25)$ & & 0.000 \\
\hline
\end{tabular}

Table 3. Results of meta-regression and subgroup analysis by age and therapy duration. PAH, predicted adult height; HtSDS-BA, height standard deviation score for bone age.

meta-analysis is the first report that the effects of GnRHa plus rhGH adjunctive therapy on outcome measurements (including height, PAH and/or HtSDS-BA) were influenced by patients' age and treatment duration.

The efficacy of GnRHa plus rhGH adjunctive therapy has been previously described in the literature ${ }^{16,44,45}$ and is consistent with the hypothesis that rhGH compensates the reduced levels of GH and/or IGF-1, which results in final adult height increase. One recent study assessed height outcome between the GnRHa plus rhGH and placebo group in adolescents with relatively early puberty. Inconsistent with our results, they found that final height standard deviation score (SDS) $[-2.0(1.0)$ vs. - 2.3 (0.6)] was not different between the combined treatment and the placebo group ${ }^{41}$. In our present meta-analysis, patients were exclusively diagnosed with CPP before the age of 8 years in girls. In contrast, van Gool and colleagues included adolescents with moderately early puberty (with Tanner stage 2-3, age less than 12 years for girls or less than 13 years for boys). Had we used a similar approach, it might have influenced the reported efficacy of the combined treatment.

For girls with CPP who show a marked decrease in GV, evidence indicates that the addition of rhGH to $\mathrm{GnRHa}$ is significantly more effective in improving height, and PAH than GnRHa alone ${ }^{12}$. One very recent study published in 2015 reported the combined treatment group showed a greater height increment during treatment in Korean girls compared to the GnRHa alone group ${ }^{46}$. In 2003, Pucarelli and colleagues ${ }^{47}$ found that the height gain in the combined treatment group was $6 \mathrm{~cm}$ higher than the GnRHa alone group. Final adult height in this study was defined as the height when growth was less than $1 \mathrm{~cm} /$ year with a bone age of over 15 years old ${ }^{48}$. Our meta-analysis showed that compared with GnRHa treatment alone, administration of GnRHa plus rhGH led to a significant increase in height and PAH of about $4 \mathrm{~cm}$, lower than the findings from the study by Pucarelli and colleagues. This difference is likely due to the longer treatment duration (2-4 years) and long-term follow-up of their study than those included in our present meta-analysis. It may also be noted that two RCTs also reported final height in adopted girls with early or precocious puberty ${ }^{49,50}$. The differences in final height between the groups treated with GnRHa with or without rhGH were all around $3 \mathrm{~cm}$. One meta-analysis published in 2014 by $\mathrm{Li}$ and coworkers pooled these two RCTs and focused on the comparison between the GnRHa and control group, in contrast to the objectives of our present meta-analysis ${ }^{51}$. Nevertheless, they also reported no significant difference in the final height SDS and initial height SDS when comparing the combined treatment group with GnRHa alone [pooled standard difference means $=-0.28,95 \% \mathrm{CI}(-0.74,0.19), P=0.243$ ]. However, according to our strict inclusion criteria, some girls included in these two studies (with early or precocious puberty with age between 6 to 12 years old) would not be diagnosed as CPP. Only Chinese girls younger than 8 years old with CPP were included in our meta-analysis. Finally, those studies were not stratified to assess associations between patients' age and outcome measurements including height and/or PAH, as we have done.

On subgroups analysis, we found that the combined therapy had significantly increased efficacy in subjects with initial treatment age younger than 10 years old. Consistent with our findings, several studies also found that adult height outcome is influenced negatively by the age at which treatment starts ${ }^{52}$. The Lawson Wilkins Pediatric Endocrine Society and the European Society for Pediatric Endocrinology stated that the efficacy of GnRHa in increasing adult height is undisputed only in early-onset CPP for girls less than 6 years old ${ }^{7}$. In girls younger than 6 years old with onset of puberty, the greatest height gain reported was $9-10 \mathrm{~cm}^{8,53}$. The guidelines for the diagnosis and treatment of growth hormone deficiency suggested that these patients should be treated with rhGH as soon as possible ${ }^{54}$. Because of the very limited data discussing the efficacy in girls less than 6 years old, it was 


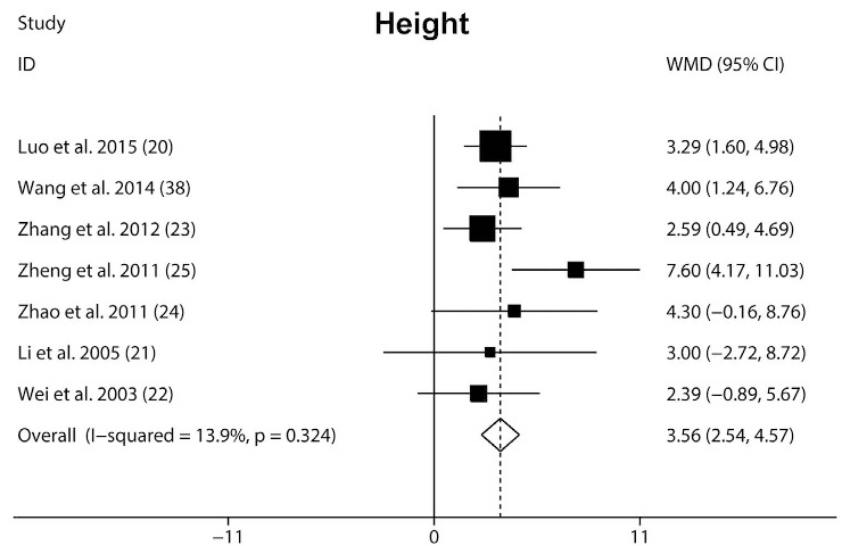

PAH

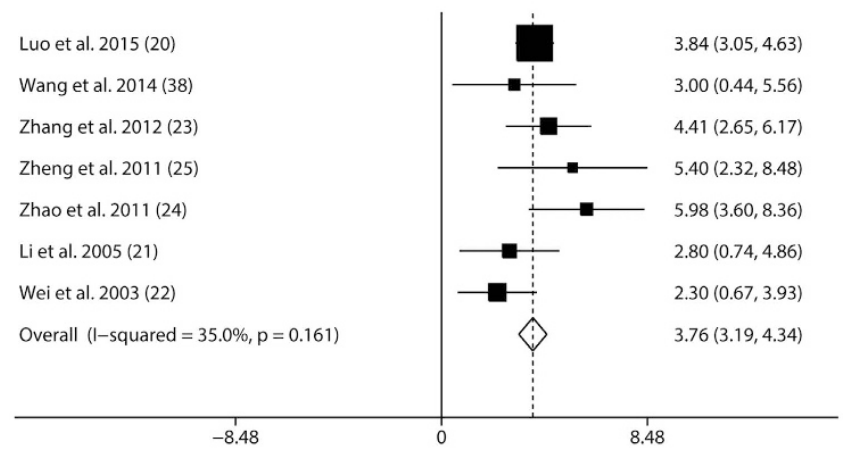

HtSDS-BA

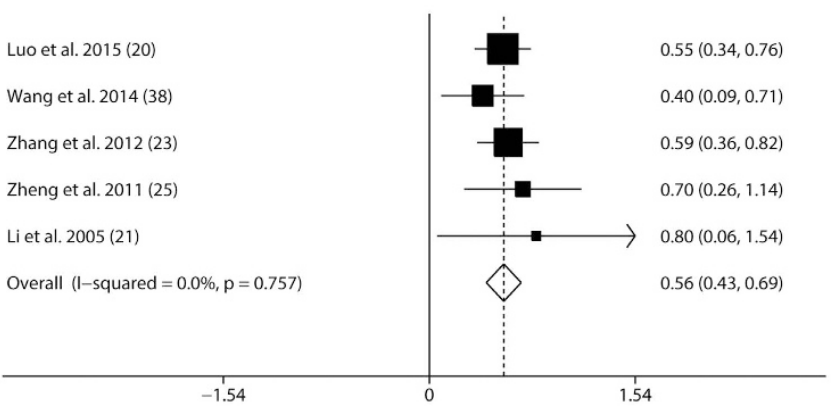

Figure 3. Fixed-effects meta-analysis of GnRHa plus rhGH vs. GnRHa alone treatment on Height, PAH and HtSDS-BA. The vertical line indicated no treatment effect. Squares and horizontal lines represent the point estimated with associated $95 \% \mathrm{CI}$ for each comparison, respectively. Diamonds represent the random effects pooled WMD for each outcome. WMD, weighted mean difference; PAH, predicted adult height; HtSDS-BA, height standard deviation score for bone age.

not possible to conduct subgroup analyses with age stratification at 6 years old. In most studies, the age of starting either GnRHa therapy of children with CPP, or rhGH therapy for children with growth hormone deficiency (GHD), was 3 to 4 years older than the "recommended" optimal age ${ }^{7}$, consistent with the mean age (9 years) of subjects included in the present meta-analysis. For the age groups included in this study, we found that girls less than 10 years old had higher height, PAH and HtSDS-BA at the end of the treatment.

We conducted further subgroup analyses based on the treatment duration (12 month) when enough studies were available. Larger improvements were seen in subjects with treatment lasting over 12 months as compared with treatment less than 12 months. Since the dose of GnRHa among all included studies ranged from $0.03 \mathrm{mg} / \mathrm{kg}^{\star}$ day to $0.05 \mathrm{mg} / \mathrm{kg}^{\star}$ day, it is not possible to perform subgroup analysis to determine whether the dose of GnRHa might also influence the efficacy. Although studies on GnRHa have accumulated over two decades, evidence of effects in boys is sparse in studies from both China and Western countries. Only two out of 464 subjects involved in our present meta-analysis were boys. We also lack data to test the psychological influence of the combined treatment of GnRHa plus rhGH on children with CPP. 


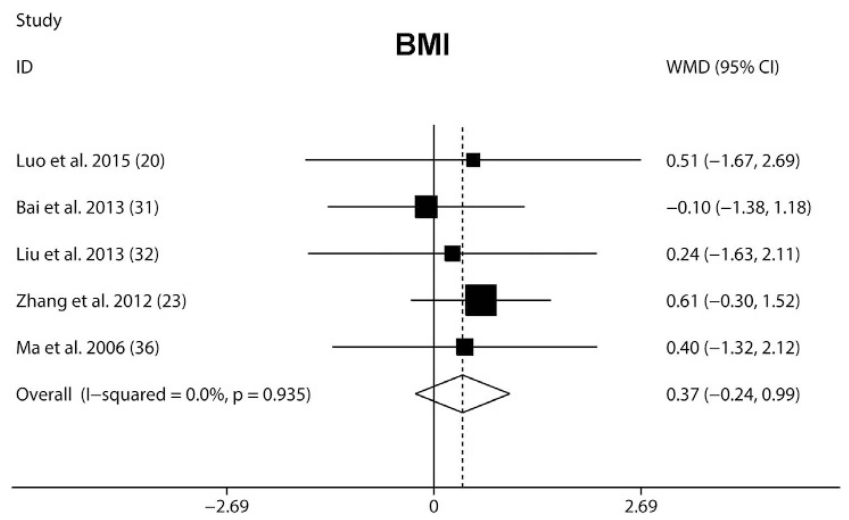

Figure 4. Fixed-effects meta-analysis of GnRHa plus rhGH adjunctive treatment on BMI. The vertical line indicated no treatment effect. Squares and horizontal lines represent the point estimated with associated 95\% CI for each comparison, respectively. Diamonds represent the random effects pooled WMD for each outcome. WMD, weighted mean difference; BMI, body mass index.

Few adverse effects have been reported for rhGH and GnRHa combined treatment, though conclusions must be cautious because of the invasive and expensive nature of the treatment. The safety of co-administration of GnRHa plus rhGH on metabolic parameters and the hypothalamic-pituitary-gonadal axis was confirmed in one large cohort of patients with CPP with a long-term follow-up ${ }^{47}$. One recent study showed that combined treatment did not affect BMI, which was consistent with our findings $\left[0.49 \mathrm{~kg} / \mathrm{m}^{2}(-0.21,1.20)\right]^{41}$. Additionally, hipbone mineral density was not significantly changed in the treated group when compared with the placebo group. Similarly, in our meta-analysis, few adverse effects were seen in included studies. The expensive nature of this treatment is also an important consideration in the clinical setting. Toumba and coworkers reported that girls with CPP reached their target height and had a total height gain of $5 \mathrm{~cm}$. Each centimeter cost about $€ 2700$ $(\$ 3500)$ per patient ${ }^{55}$. However, we need more data to definitively evaluate the financial burden based on the therapeutic effect. Currently, the therapeutic strategy should be tailored to individual patients of CPP.

Three necessary and important diagnostic criteria of CPP were used by all included studies: firstly, early appearance of secondary sexual characteristics in girls before 8 years (boys before 9 years); secondly, GnRH stimulation test indicating $\mathrm{LH}>12 \mathrm{IU} / \mathrm{L}$ ( $\mathrm{LH}>25 \mathrm{IU} / \mathrm{L}$ in boys), and the ratio of LH/FSH between 0.6 to 1.0; lastly, enlarged gonads with pelvic ultrasound showing increased ovarian volume $>1 \mathrm{ml}$ and several ovarian follicle with diameter $>4 \mathrm{~mm}$ (enlarged testicular volume $\geq 4 \mathrm{ml}$ in boys). The second and third criteria are critical to prevent unnecessary treatment of children with premature adrenarche or adiposity-related changes in the absence of awakening of the HPG axis. All included studies identified their patients as having idiopathic CPP except Fang's study ${ }^{37}$. Limitations of the present study require these results to be interpreted with caution. While results on height, PAH and HtSDS-BA were reported, available studies lacked reports of final adult height. Since most of the eligible studies were of short treatment duration ( $\leq 2$ years), the results may not persist with long-term follow-up. In addition, publication bias might contribute to underestimation of the effect size. Lastly, given that the included studies were case-control or observational studies, more powerful RCTs are needed to evaluate the efficacy of the combined treatment for CPP.

Animal studies raise the concern that increasing IGF-1 levels could further advance puberty. These studies suggest that IGF-1 regulates the precise temporal and spatial development of GnRH neurons and GnRH neurosecretion ${ }^{56}$. Male and female mice with the IGF-1R deleted in GnRH neurons demonstrated delayed pubertal development. With IGF-1 administration to prepubertal juveniles, puberty was advanced in control females, but not in females with the IGF-1R deleted in GnRH neurons, suggesting that activation of IGF-1 signaling within the GnRH neuron is a primary trigger for increasing $\mathrm{GnRH}$ release at puberty ${ }^{57}$. In contrast, IGF-1 administration was unable to advance puberty in control males. Additionally, a recent rat study demonstrated that IGF-1 could also regulate $\mathrm{LH}$, and presumably $\mathrm{GnRH}$, release by modulation of Kisspeptin and N-methyl-D-aspartate -mediated neurotransmission ${ }^{58}$. Further studies are needed to elucidate these mechanisms. While studies have not conclusively demonstrated that IGF-1 advances human puberty, in healthy girls, higher childhood IGF-1 levels predict earlier age at menarche ${ }^{59}$, and girls with CPP have increased IGF-1 levels compared with age, BA, and pubertal stage-matched healthy girls ${ }^{60}$. Nevertheless, in accord with findings of direct actions of IGF-1 on GnRH neurons and upstream neuronal targets, the current analysis shows that GnRHa treatment effectively prevents any advancement of puberty that elevated IGF-1 levels might otherwise induce.

\section{Conclusion}

Better understanding of the efficacy and safety of the addition of rhGH to GnRHa in treatment of children with $\mathrm{CPP}$ will allow for improvements in final height, PAH, HtSDS-BA and the psychosocial care of such children. The present systemic review and meta-analysis provides evidence that the addition of rhGH to GnRHa in therapy for children with CPP is superior to either baseline or GnRHa treatment alone. The efficacy of the combined therapy is increased with use in subjects with initial treatment age younger than 10 years old, or with prolonged therapy duration. No obvious adverse effects occurred with respect to the published studies. These findings may aid clinicians in making treatment decisions in the treatment of children with CPP in this population and spur 
further investigation of the impact of the addition of rhGH to GnRHa. Ultimately, multi-center, long-term, and well-designed studies are needed to further understand the mechanism, the efficacy, and the safety of the addition of rhGH to GnRHa during CPP therapy.

\section{References}

1. Carel, J. C. \& Leger, J. Clinical practice. Precocious puberty. N Engl J Med 358, 2366-2377, doi: 10.1056/NEJMcp0800459 (2008).

2. Parent, A. S. et al. The timing of normal puberty and the age limits of sexual precocity: variations around the world, secular trends, and changes after migration. Endocr Rev 24, 668-693, doi: 10.1210/er.2002-0019 (2003).

3. Kim, S. H., Huh, K., Won, S., Lee, K. W. \& Park, M. J. A significant increase in the incidence of central precocious puberty among Korean girls from 2004 to 2010. Plos One 10, e0141844, doi: 10.1371/journal.pone.0141844 (2015).

4. Kletter, G. B. \& Kelch, R. P. Clinical review 60: Effects of gonadotropin-releasing hormone analog therapy on adult stature in precocious puberty. J Clin Endocrinol Metab 79, 331-334, doi: 10.1210/jcem.79.2.8045943 (1994).

5. Oostdijk, W. et al. Final height in central precocious puberty after long term treatment with a slow release GnRH agonist. Arch Dis Child 75, 292-297 (1996).

6. Oerter, K. E. et al. Adult height in precocious puberty after long-term treatment with deslorelin. J Clin Endocrinol Metab 73, 1235-1240, doi: 10.1210/jcem-73-6-1235 (1991).

7. Carel, J. C. et al. Consensus statement on the use of gonadotropin-releasing hormone analogs in children. Pediatrics 123, e752-762, doi: 10.1542/peds.2008-1783 (2009).

8. Klein, K. O., Barnes, K. M., Jones, J. V., Feuillan, P. P. \& Cutler, G. B., Jr. Increased final height in precocious puberty after long-term treatment with LHRH agonists: the National Institutes of Health experience. J Clin Endocrinol Metab 86, 4711-4716, doi: 10.1210/ jcem.86.10.7915 (2001).

9. Walvoord, E. C. \& Pescovitz, O. H. Combined use of growth hormone and gonadotropin-releasing hormone analogues in precocious puberty: theoretic and practical considerations. Pediatrics 104, 1010-1014 (1999).

10. Tato, L. et al. Use of combined Gn-RH agonist and hGH therapy for better attining the goals in precocious puberty treatment. Horm Res 44 Suppl 3, 49-54 (1995).

11. Saggese, G., Bertelloni, S., Baroncelli, G. I., Di Nero, G. \& Battini, R. Growth velocity and serum aminoterminal propeptide of type III procollagen in precocious puberty during gonadotropin-releasing hormone analogue treatment. Acta Paediatr 82, 261-266 (1993).

12. Pasquino, A. M. et al. Combined treatment with gonadotropin-releasing hormone analog and growth hormone in central precocious puberty. J Clin Endocrinol Metab 81, 948-951, doi: 10.1210/jcem.81.3.8772556 (1996).

13. Muller, J., Juul, A., Andersson, A. M., Sehested, A. \& Skakkebaek, N. E. Hormonal changes during GnRH analogue therapy in children with central precocious puberty. J Pediatr Endocrinol Metab 13 Suppl 1, 739-746 (2000).

14. Wu, J. M., Yu, J. \& Yang, Y. Gene expression related to growth axis and gonadal axis in puberty rats. Zhong Xi Yi Jie He Xue Bao 1, 35-38 (2003).

15. Cara, J. F., Burstein, S., Cuttler, L., Moll, G. W., Jr. \& Rosenfield, R. L. Growth hormone deficiency impedes the rise in plasma insulinlike growth factor I levels associated with precocious puberty. J Pediatr 115, 64-68 (1989).

16. Pasquino, A. M., Pucarelli, I., Segni, M., Matrunola, M. \& Cerroni, F. Adult height in girls with central precocious puberty treated with gonadotropin-releasing hormone analogues and growth hormone. J Clin Endocrinol Metab 84, 449-452, doi: 10.1210/ jcem.84.2.5431 (1999).

17. Kohn, B., Julius, J. R. \& Blethen, S. L. Combined use of growth hormone and gonadotropin-releasing hormone analogues: the national cooperative growth study experience. Pediatrics 104, 1014-1018 (1999).

18. Oostdijk, W. et al. Long-term results with a slow-release gonadotrophin-releasing hormone agonist in central precocious puberty. Dutch-German Precocious Puberty Study Group. Acta Paediatr Scand Suppl 372, 39-45; discussion 46 (1991).

19. Volta, C., Regazzi, C., Ndaka, J., Vitale, R. \& Bernasconi, S. Combined therapy with luteinizing hormone releasing hormone agonist (LHRHa) and growth hormone (GH) in central precocious puberty. Acta Biomed 76, 73-78 (2005).

20. Luo, X. Clinical effect of GnRHa combined with recombinant human growth hormone (rhGH) in the treatment of idiopathic central precocious puberty (ICPP) in girls. China Modern Medicine 22, 107-109 (2015)

21. Li, Y., Liang, L., Sun, L. \& Dong, G. Treatment of post-menarche idiopathic central precocious puberty in girls with combined gonadotropin-releasing hormone analog and growth hormone. Chinese Journal of Pediatrics 43, 108-112 (2005).

22. Wei, Q., Zhou, Z. \& Li, Y. Effects of treatment on idiopathic central precocious puberty with gonadotropin-releasing hormone analogue and growth hormone. Medical Information 16, 328-329 (2003).

23. Zhang, L. \& Chen, Z. The observation of combined use of gonadotropin-releasing hormone analogues and growth hormone in central precocious puberty. Fudan University Master's Thesis (2012).

24. Zhao, Y., Zhang, Q. \& Gao, X. The effect of recombinant human growth hormone on height during the GnRHa treatment for idiopathic central precocious puberty. Shandong Medical Journal 51, 60-61 (2011).

25. Zheng, P. et al. Final adult height in girls with idiopathic central precocious puberty treated with gonadotropin-releasing hormone analogue and growth hormone. Chinese Journal of Endocrinology and Metabolism 27, 287-291 (2011).

26. Green, S. Cochrane Handbook for Systematic Reviews of Interventions Version 5.1.0 [updated March 2011]. The Cochrane Collaboration (2011).

27. Higgins, J. P., Thompson, S. G., Deeks, J. J. \& Altman, D. G. Measuring inconsistency in meta-analyses. BMJ 327, 557-560, doi: 10.1136/bmj.327.7414.557 (2003).

28. Deeks J, A. D. \& Bradburn, M. Statistical methods for examining heterogeneity and combining results from several studies in metaanalysis. In Egger M. (eds) London: BMJ Books (2001).

29. Egger, M., Davey Smith, G., Schneider, M. \& Minder, C. Bias in meta-analysis detected by a simple, graphical test. BMJ 315, 629-634 (1997).

30. Sutton, A. J., A. K., Jones, D. R., Sheldon T. A. \& Song F. Methods for meta-analysis in medical research. Chichester: Wiley. (2000).

31. Bai, H. Effect of combined treatment with gonadotropin-releasing hormone analogues and growth hormone in central precocious puberty. Shandong Medical Journal 53, 89-90 (2013).

32. Liu, H. \& Wang, Z. The efficacy of growth hormone in idiopathic central precocious puberty. Strait Journal of Preventive Medicine $19,80-81(2013)$

33. Sun, X., Wu, J., Yang, F., Li, P. \& Wang, X. Effects of treatment on female idiopathic central precocious puberty with gonadotrophinereleasing hormone analogue and growth hormone. Chinese Journal of Child Health Care 20, 731-734 (2012).

34. $\mathrm{Wu}, \mathrm{Q}$. The efficacy observation of combining GnRHa with rhGH to treat the big bone age female idiopathic precocious puberty. China Modern Medicine 19, 75-76 (2012).

35. Liu, C. \& Li, G. The effect of height improvement treated with GnRHa and rhGH in girls with big bone age of idiopathic central precocious puberty. Shandong University Master's Thesis (2011).

36. Ma, H., Du, M., Li, Y., Su, Z. \& Chen, S. Evaluation of combined treatment of gonadotropin-releasing hormone analog with recombinant human growth hormone in girls with central precocious puberty. Clin J Endocrinol Metab 22, 252-255 (2006).

37. Fang, L., Yao, G., Jin, Y., Zhu, Z. \& Zheng, Z. Effect of short term of combined treatment with Gonadotropin-releasing hormone analogues and Growth hormone in central precocious puberty. Journal of Biology 18, 19-20 (2001) 
38. Wang, C. et al. Effects of gonadotropin releasing hormone analog and growth hormone on height in girls with idiopathic centralprecocious puberty. Chin J Contemp Pediatr 16, 25-30 (2014).

39. Tonini, G. \& Lazzerini, M. Side effects of GnRH analogue treatment in childhood. J Pediatr Endocrinol Metab 13 Suppl 1, 795-803 (2000).

40. Carel, J. C. et al. Treatment of central precocious puberty by subcutaneous injections of leuprorelin 3-month depot (11.25 mg). J Clin Endocrinol Metab 87, 4111-4116, doi: 10.1210/jc.2001-020243 (2002).

41. van Gool, S. A. et al. Final height outcome after three years of growth hormone and gonadotropin-releasing hormone agonist treatment in short adolescents with relatively early puberty. J Clin Endocrinol Metab 92, 1402-1408, doi: 10.1210/jc.2006-2272 (2007).

42. Lem, A. J., van der Kaay, D. C. \& Hokken-Koelega, A. C. Bone mineral density and body composition in short children born SGA during growth hormone and gonadotropin releasing hormone analog treatment. J Clin Endocrinol Metab 98, 77-86, doi: 10.1210/ jc.2012-2492 (2013).

43. Liu, H. et al. Systematic review: the safety and efficacy of growth hormone in the healthy elderly. Ann Intern Med 146, 104-115 (2007).

44. Saggese, G. et al. Effect of combined treatment with gonadotropin releasing hormone analogue and growth hormone in patients with central precocious puberty who had subnormal growth velocity and impaired height prognosis. Acta Paediatr 84, 299-304 (1995).

45. Toumba, M., Bacopoulou, I., Savva, S. C. \& Skordis, N. Efficacy of combined treatment with growth hormone and gonadotropin releasing hormone analogue in children with poor prognosis of adult height. Indian Pediatr 44, 497-502 (2007).

46. Gyon, Y., Yun, Y. J., Kim, Y. D. \& Han, H. S. Age at menarche and near final height after treatment with gonadotropin-releasing hormone agonist alone or combined with growth hormone in Korean girls with central precocious puberty. Clin Pediatr Endocrinol 24, 175-183, doi: 10.1297/cpe.24.175 (2015).

47. Pucarelli, I., Segni, M., Ortore, M., Arcadi, E. \& Pasquino, A. M. Effects of combined gonadotropin-releasing hormone agonist and growth hormone therapy on adult height in precocious puberty: a further contribution. J Pediatr Endocrinol Metab 16, 1005-1010 (2003).

48. Pucarelli, I. et al. Combined therapy with GnRH analog plus growth hormone in central precocious puberty. J Pediatr Endocrinol Metab 13 Suppl 1, 811-820 (2000).

49. Tuvemo, T. et al. Final height after combined growth hormone and GnRH analogue treatment in adopted girls with early puberty. Acta Paediatr 93, 1456-1462, doi: 10.1080/08035250410021793 (2004).

50. Mul, D., Oostdijk, W., Waelkens, J. J., Schulpen, T. W. \& Drop, S. L. Gonadotrophin releasing hormone agonist treatment with or without recombinant human GH in adopted children with early puberty. Clin Endocrinol (Oxf) 55, 121-129 (2001).

51. Li, P., Li, Y. \& Yang, C. Gonadotropin releasing hormone agonist treatment to increase final stature in children with precocious puberty: a meta-analysis. Medicine (Baltimore) 93, e260, doi: 10.1097/MD.0000000000000260 (2014).

52. Mauras, N. et al. Anastrozole increases predicted adult height of short adolescent males treated with growth hormone: a randomized, placebo-controlled, multicenter trial for one to three years. J Clin Endocrinol Metab 93, 823-831, doi: 10.1210/jc.2007-1559 (2008).

53. Lazar, L., Padoa, A. \& Phillip, M. Growth pattern and final height after cessation of gonadotropin-suppressive therapy in girls with central sexual precocity. J Clin Endocrinol Metab 92, 3483-3489, doi: 10.1210/jc.2007-0321 (2007).

54. Growth Hormone Research, S. Consensus guidelines for the diagnosis and treatment of growth hormone (GH) deficiency in childhood and adolescence: summary statement of the GH Research Society. GH Research Society. J Clin Endocrinol Metab 85, 3990-3993, doi: 10.1210/jcem.85.11.6984 (2000).

55. Toumba, M., Kokotsis, V., Savva, S. C. \& Skordis, N. Expensive therapies in children: benefit versus cost of combined treatment of recombinant human growth hormone and gonadotropin-releasing hormone analogue in girls with poor height potential. J Pediatr Endocrinol Metab 27, 311-316, doi: 10.1515/jpem-2013-0210 (2014).

56. Onuma, T. A. et al. Regulation of temporal and spatial organization of newborn GnRH neurons by IGF signaling in zebrafish. $J$ Neurosci 31, 11814-11824, doi: 10.1523/JNEUROSCI.6804-10.2011 (2011).

57. Divall, S. A. et al. Divergent roles of growth factors in the GnRH regulation of puberty in mice. J Clin Invest 120, 2900-2909, doi: 10.1172/JCI41069 (2010)

58. Neal-Perry, G., Yao, D., Shu, J., Sun, Y. \& Etgen, A. M. Insulin-like growth factor-I regulates LH release by modulation of kisspeptin and NMDA-mediated neurotransmission in young and middle-aged female rats. Endocrinology 155, 1827-1837, doi: 10.1210/ en.2013-1682 (2014)

59. Tam, C. S., de Zegher, F., Garnett, S. P., Baur, L. A. \& Cowell, C. T. Opposing influences of prenatal and postnatal growth on the timing of menarche. J Clin Endocrinol Metab 91, 4369-4373, doi: 10.1210/jc.2006-0953 (2006)

60. Sorensen, K., Aksglaede, L., Petersen, J. H., Andersson, A. M. \& Juul, A. Serum IGF1 and insulin levels in girls with normal and precocious puberty. Eur J Endocrinol 166, 903-910, doi: 10.1530/EJE-12-0106 (2012).

\section{Acknowledgements}

We express our gratitude to all participants in this study.

\section{Author Contributions}

M.J.W., D.L., Y.J.Z. and J.W.H. conceived the study idea and participated in the study design. M.J.W. and Y.J.Z. conducted literature search, reviewed and extracted data and carried out the statistical analysis. D.L. and J.W.H. provided critical comments for the conduct of the study. M.J.W. drafted the article. D.L., J.W.H. and Y.J.Z. revised the article. All authors read and approved the final manuscript.

\section{Additional Information}

Competing financial interests: The authors declare no competing financial interests.

How to cite this article: Wang, M. et al. The Efficacy of GnRHa Alone or in Combination with rhGH for the Treatment of Chinese Children with Central Precocious Puberty. Sci. Rep. 6, 24259; doi: 10.1038/srep24259 (2016).

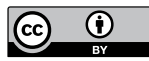

This work is licensed under a Creative Commons Attribution 4.0 International License. The images or other third party material in this article are included in the article's Creative Commons license, unless indicated otherwise in the credit line; if the material is not included under the Creative Commons license, users will need to obtain permission from the license holder to reproduce the material. To view a copy of this license, visit http://creativecommons.org/licenses/by/4.0/ 